\title{
Internal transcribed spacer (ITS) sequencing reveals considerable fungal diversity in dairy products
}

\author{
A. J. Buehler, R. L. Evanowski, N. H. Martin, K. J. Boor, and M. Wiedmann ${ }^{1}$ \\ Milk Quality Improvement Program, Department of Food Science, Cornell University, Ithaca, NY 14853
}

\begin{abstract}
Fungi are important spoilage organisms in dairy products. However, little is known about the diversity of naturally occurring spoilage fungi in raw milk and processed dairy products, due at least in part to the fact that classical fungal identification methods require considerable expertise. To gain further insight into the fungal diversity in the dairy system, we isolated fungi from raw milk, raw and pasteurized milk cheese, and yogurt using the selective dichloran rose bengal chloramphenicol agar. In total, 361 fungal isolates were obtained and further characterized by DNA sequencing of the internal transcribed spacer (ITS) region and the nuclear ribosomal large subunit (LSU) rRNA gene if needed. We conducted BLAST (https://blast.ncbi.nlm .nih.gov/Blast.cgi) searches of the ITS region sequences against the UNITE Database (https://unite.ut.ee/ analysis.php), and selected other databases if needed, which allowed identification to the species level of 183 isolates and to the genus level of 107 of the 346 isolates that were successfully ITS sequenced. The isolates characterized represented 3 phyla and 19 genera; the most common genera isolated were Penicillium (25\% of isolates), Debaryomyces (18\%), and Candida (9\%). This study not only provides, by using modern molecular tools, a baseline understanding of the types of fungi in dairy products, but also confirms that ITS sequencing is a useful approach for identification of fungal organisms found in the dairy food chain.
\end{abstract}

Key words: fungi, internal transcribed spacer (ITS) sequencing, yeast, mold

\section{INTRODUCTION}

Dairy products have a long history of spoilage by yeasts and molds, but as shelf lives and distribution chains are extended, these microorganisms have become increasingly problematic for the dairy industry.

Received January 24, 2017.

Accepted August 2, 2017.

${ }^{1}$ Corresponding author: mw16@cornell.edu
Some reports estimate that 5 to $10 \%$ of all food produced is lost to fungal spoilage worldwide (Pitt and Hocking, 2009). Although specific estimates for dairy product loss due to fungal spoilage do not appear to be available, cultured dairy products, such as yogurt and cheese, are well documented to be susceptible to spoilage by fungi because of the ability of many strains to grow at the low temperature and $\mathrm{pH}$ encountered in these products (Fröhlich-Wyder, 2003; Mayoral et al., 2005; Banjara et al., 2015). Additionally, many cheeses have reduced water activity and high salt concentrations, which provides a unique niche for the growth of yeasts and molds (Gardini et al., 2006; Ledenbach and Marshall, 2009). Fungal spoilage organisms produce degradative enzymes that break down lipids, proteins, and carbohydrates, leading to a variety of undesirable sensorial qualities (Ledenbach and Marshall, 2009). In addition, fungal spoilage is often easily visually detected by consumers; and with broad use of the internet, communication of fungal spoilage via pictures shared on social media is increasingly common and has considerable potential to damage the reputation of dairy products (Newkirk et al., 2012).

Sources of yeast and mold contamination of dairy products typically appear to be the air and other environmental sources in processing facilities and other environments (e.g., aging facilities, retail; Kure et al., 2001). Airborne mold has been reported to enter the processing environment from either the outdoor air via the ventilation system or from moist niches present in the process environment (Kure et al., 2008). In the presence of prolonged elevated indoor moisture content, some fungi can grow and sporulate, resulting in further contamination in the indoor environment (Pitkäranta et al., 2008). Fungal environmental contamination in processing plants has previously been documented (Lund et al., 2003; Temelli et al., 2006). For example, Lund et al. (2003) collected swab and air samples from cheese production plants, the processing environment, and contaminated cheese products and identified the packaging environment and the coating step as the major points for fungal environmental contamination. In another study, Temelli et al. (2006) reported the cold 
room and production room air as sources for fungal environmental contamination in Turkish white cheese. Based on these findings, air in the processing plant represents an important source of fungal contamination.

Yeasts and molds are also commonly found in the dairy farm environment and can appear as natural contaminants in raw milk (Fleet, 1990; Lavoie et al., 2012; Atanassova et al., 2016). Most authors suggest, however, that fungi found in raw milk are typically heat sensitive and that raw milk is thus not an important (direct) source of fungi found in dairy products (Jacques and Casaregola, 2008). A few studies have surveyed the diversity of fungi in raw milk and reported that yeasts are more frequently isolated from raw milk than molds (Callon et al., 2007; Delavenne et al., 2011; Panelli et al., 2013). For example, Panelli et al. (2013) tested 40 bulk milk samples across the Italian Alps and most frequently isolated Kluyveromyces marxianus, Atrotorquata lineata, and Candida spp. Importantly, these studies identified some fungal species that had not previously been found in raw milk, suggesting that the fungal diversity associated with raw milk remains to be fully understood.

Historically, methods used to identify fungal microorganisms have involved visual and labor intensive phenotypic characterization, which requires extensive training and experience to master (Pitkäranta et al., 2008). Standardized DNA sequencing methods, sometimes referred to as DNA barcoding, represent robust and rapid methods for fungal identification. Moreover, an accepted universal internal transcribed spacer (ITS) region barcode for fungi has been well documented to allow for reproducible and discriminatory DNA sequencing-based fungal identification (Mayoral et al., 2005; Schoch et al., 2012; Sulaiman et al., 2014).

The objective of this study was (1) to implement molecular characterization methods for dairy-associated fungi isolated from raw milk, raw and pasteurized milk cheeses, and yogurt products; and (2) to use these methods to provide initial insights into the fungal diversity associated with different dairy products.

\section{MATERIALS AND METHODS}

\section{Sample Collection}

Using a convenience sampling approach, samples of bulk tank raw milk, cheese, and yogurt were collected between April and September 2015 and used for isolation of yeast and mold (see Table 1 for details on samples collected). Bulk tank raw milk samples (300 $\mathrm{mL}$ each) were collected from 8 dairy farms in New York State. Raw and pasteurized cheese samples (14 and 33 , respectively) were collected from producers, supermarkets, wholesale distributors, and specialty shops in the state, excluding cheeses that were intentionally inoculated with fungi (e.g., mold-ripened cheeses). Yogurt samples $(\mathrm{n}=30)$ representing plain, fruit, and other varieties were also conveniently collected from producers; none of the samples were visually spoiled at the time of collection. Samples were stored at $4^{\circ} \mathrm{C}$ until they were analyzed.

\section{Fungal Isolation}

Raw milk samples were plated directly on dichloran rose bengal chloramphenicol agar (DRBC; Becton, Dickinson and Co., Sparks, MD). Additionally, two 200-mL enrichments were prepared, each consisting of $100 \mathrm{~mL}$ of malt extract broth (Becton, Dickinson and Co.), with $40 \mathrm{mg} / \mathrm{L}$ streptomycin sulfate (Sigma, St. Louis, MO) and $100 \mathrm{~mL}$ of raw milk. Enrichments were prepared in sample bags and homogenized by hand for $30 \mathrm{~s}$ before incubation; one enrichment was incubated at $25 \pm 2^{\circ} \mathrm{C}$ for $72 \mathrm{~h}$ and the other was incubated at $18 \pm 2^{\circ} \mathrm{C}$ for $120 \mathrm{~h}$. After these incubations, undiluted and serially diluted enrichments were spread plated on $\mathrm{DRBC}$, followed by incubation at $25 \pm 2^{\circ} \mathrm{C}$ for $120 \mathrm{~h}$.

Cheese samples were tested by mixing approximately $20 \mathrm{~g}$ of cheese with $20 \mathrm{~mL}$ of malt extract broth (containing $40 \mathrm{mg} / \mathrm{L}$ streptomycin sulfate) in a sampling bag (prepared in duplicate), followed by homogenization at $260 \mathrm{rpm}$ for $60 \mathrm{~s}$ in a Stomacher 400 Circulator (Seward Ltd., Worthing, UK). One homogenized enriched cheese sample was plated directly on DRBC and incubated at $25 \pm 2^{\circ} \mathrm{C}$ for $120 \mathrm{~h}$. In addition, the 2 homogenized sample enrichments were incubated at $25 \pm 2^{\circ} \mathrm{C}$ for $72 \mathrm{~h}$ or $18 \pm 2^{\circ} \mathrm{C}$ for $120 \mathrm{~h}$. After these incubations, undiluted enrichments were spread plated on DRBC and then incubated at $25 \pm 2^{\circ} \mathrm{C}$ for $120 \mathrm{~h}$.

Yogurt samples were diluted 1:10 in PBS (Weber Scientific, Hamilton, NJ) in a sampling bag, followed by homogenization at $260 \mathrm{rpm}$ for $60 \mathrm{~s}$ in a Stomacher 400 Circulator (Seward Ltd.). Each homogenized diluted yogurt sample was spread plated directly on DRBC and incubated at $25 \pm 2^{\circ} \mathrm{C}$ for $120 \mathrm{~h}$.

For all sample types, fungal colonies present on DRBC were visually examined, and colonies with distinct morphologies were selected and streaked for purity on malt extract agar (Becton, Dickinson and Co.). For each sample, DRBC plates were evaluated separately to select unique phenotypes from both direct plating and enrichment for further characterization. Per sample, between 0 and 10 isolates (average of 2 isolates) were collected from direct plating and between 0 and 11 isolates (average of 3 isolates) were collected from 
sample enrichments (Supplemental Table S1; https:// doi.org/10.3168/jds.2017-12635). All isolates were then frozen at $-80^{\circ} \mathrm{C}$ in $15 \%$ glycerol. Isolate characteristics, including nucleotide sequences, and relevant sample information are available through the Food Microbe Tracker database at www.foodmicrobetracker.com (Vangay et al., 2013); http://www.foodmicrobetracker .com/search/display_list.aspx?refid $=505$ provides a direct link to all 361 isolates reported here.

\section{ITS Sequencing}

Isolates obtained as described above were characterized by DNA sequencing of the ITS region, using the ITS primers described by Schoch et al. (2012). Briefly, purified DNA for PCR was prepared for each isolate from 120-h cultures on malt extract agar using the PowerSoil DNA Isolation Kit (MO BIO, Carlsbad, CA). The PCR conditions were slightly modified from

Table 1. Dairy products sampled for yeast and mold

\begin{tabular}{|c|c|c|c|c|c|c|c|}
\hline \multirow[b]{2}{*}{$\begin{array}{l}\text { Sample } \\
\text { type }\end{array}$} & \multirow[b]{2}{*}{ Species } & \multirow[b]{2}{*}{ Origin } & \multirow[b]{2}{*}{$\begin{array}{l}\text { Raw or } \\
\text { pasteurized } \\
\text { milk }\end{array}$} & \multirow[b]{2}{*}{ Type } & \multirow[b]{2}{*}{$\begin{array}{l}\text { No. of } \\
\text { samples }\end{array}$} & \multicolumn{2}{|c|}{$\begin{array}{l}\text { No. of isolates } \\
\text { obtained by: }\end{array}$} \\
\hline & & & & & & $\begin{array}{l}\text { Direct } \\
\text { plating }\end{array}$ & Enrichment \\
\hline Raw milk & Cow & $\begin{array}{l}\text { New York State dairy } \\
\text { farms }\end{array}$ & Raw & Bulk tank & 8 & 10 & 28 \\
\hline \multirow[t]{22}{*}{ Cheese } & Cow & United States & Pasteurized & Semi-hard & 1 & 2 & 7 \\
\hline & Cow & United States & Raw & Semi-hard, natural rind & 2 & 5 & 8 \\
\hline & Cow & United States & Raw & Hard, washed rind & 1 & 0 & 4 \\
\hline & Cow & New York, United States & Raw & Soft, washed rind & 2 & 7 & 16 \\
\hline & Goat & Portugal & Pasteurized & Hard & 1 & 3 & 1 \\
\hline & Goat & Switzerland & Pasteurized & Hard & 1 & 2 & 7 \\
\hline & Goat/sheep & France & Pasteurized & Hard & 1 & 1 & 4 \\
\hline & Goat & France & Pasteurized & Semi-hard, washed rind & 1 & 1 & 6 \\
\hline & Goat & Canada & Pasteurized & Brined & 1 & 1 & 3 \\
\hline & Goat & Canada & Pasteurized & Fresh & 1 & 2 & 3 \\
\hline & Goat & France & Pasteurized & Soft & 1 & 1 & 1 \\
\hline & Goat & Italy & Raw & Hard & 1 & 2 & 4 \\
\hline & Goat & Switzerland & Raw & Semi-hard & 1 & 2 & 4 \\
\hline & Sheep & Italy & Pasteurized & Hard & 2 & 4 & 7 \\
\hline & Sheep & Spain & Pasteurized & Hard & 2 & 1 & 6 \\
\hline & Sheep & Canada & Pasteurized & Hard, natural rind & 1 & 1 & 5 \\
\hline & Sheep & France & Pasteurized & Hard, natural rind & 1 & 3 & 4 \\
\hline & Sheep & Cyprus & Pasteurized & Semi-hard & 1 & 2 & 2 \\
\hline & Sheep & France & Pasteurized & Semi-hard & 1 & 1 & 3 \\
\hline & Sheep & Italy & Pasteurized & Semi-hard & 2 & 4 & 5 \\
\hline & Sheep & Italy & Pasteurized & Semi-hard, natural rind & 2 & 3 & 7 \\
\hline & Sheep & Spain & Raw & Soft & 1 & 3 & 2 \\
\hline \multirow{3}{*}{ Yogurt } & Cow & United States & Pasteurized & & 22 & 75 & $\mathrm{NA}^{2}$ \\
\hline & Cow & United States & Pasteurized & Added fruit & 2 & 2 & NA \\
\hline & Cow & United States & Pasteurized & Added fruit and other & 6 & 6 & NA \\
\hline
\end{tabular}


Schoch et al. (2012) and consisted of 1 cycle of $95^{\circ} \mathrm{C}$ for $5 \mathrm{~min} ; 35$ cycles of $95^{\circ} \mathrm{C}$ for $1 \mathrm{~min}, 56^{\circ} \mathrm{C}$ for $1 \mathrm{~min}$, $72^{\circ} \mathrm{C}$ for $1 \mathrm{~min}$; 1 cycle of $72^{\circ} \mathrm{C}$ for $10 \mathrm{~min}$, followed by a $4^{\circ} \mathrm{C}$ hold. Amplification of PCR products was confirmed by gel electrophoresis and PCR products were purified with the ExoSAP method (Affymetrix, Santa Clara, CA). Sanger sequencing with PCR primers was performed at Cornell University's Life Sciences Core Laboratory Center (Ithaca, NY) using the ABI 3730xl DNA analyzer (Applied Biosystems, Foster City, CA). The DNA sequences were assembled and proofread in Sequencher (version 5.3, Gene Codes Corporation, Ann Arbor, MI), and high-quality, double-stranded sequence data were used for further analysis.

Sequences were aligned using MUSCLE (Edgar, 2004), and ITS fragments, ranging in length from 251 to 724 nucleotides (nt), corresponding to 2 internal transcribed spacers and the $5.8 \mathrm{~S}$ gene between them (hereafter referred to as the ITS region), were used for subsequent analyses.

\section{Nuclear Ribosomal Large Subunit Sequencing}

Isolates that could not be amplified using the ITS region primers were characterized by sequencing part of the gene that encodes the D1/D2 domain of the nuclear large subunit (LSU) (26S) ribosome, using primers NL1 and NL4 (Kurtzman and Robnett, 1998). The PCR conditions were slightly modified from Kurtzman and Robnett (1998) and consisted of 1 cycle of $94^{\circ} \mathrm{C}$ for 5 min; 36 cycles of $94^{\circ} \mathrm{C}$ for $1 \mathrm{~min}, 52^{\circ} \mathrm{C}$ for $1 \mathrm{~min}, 72^{\circ} \mathrm{C}$ for $2 \mathrm{~min}$; 1 cycle of $72^{\circ} \mathrm{C}$ for $10 \mathrm{~min}$, followed by a $4^{\circ} \mathrm{C}$ hold. The PCR products were purified and sequenced as described above for ITS sequencing.

\section{Allelic Type Assignment}

The ITS allelic types (AT) were assigned using BLAST (https://blast.ncbi.nlm.nih.gov/Blast.cgi). A unique ITS AT was assigned to every gene sequence that differed by $\geq 1$ nucleotides from any previously obtained sequence. The first isolate of each new ITS AT was designated the reference strain for that AT.

\section{Alignment, Tree Construction, and Species Identification}

For species identification, the ITS region sequences for each unique ITS AT were queried against ITS region sequences in the UNITE database (https://unite.ut.ee/ analysis.php; Kõljalg et al., 2005). The LSU sequences were queried against LSU sequences in Mycobank (http://www.mycobank.org/; Crous et al., 2004). An isolate with an identity score of $\geq 99.00 \%$ to exactly one type strain was assigned the species ID of that type strain. Isolates that had an identity score of $\geq 99.00 \%$ against more than one type strain in the same phyla were assigned the finest classification rank available (typically a genus designation but in some cases only family designations could be assigned). Identity scores between 97.00 and $99.00 \%$ were assigned a phylum; no isolates showed identity scores $<97.00 \%$.

For isolates that could not be assigned genus and species identifications from the UNITE database, Mycobank was used to allow for similarity searches against additional fungal databases. Isolates with an identity score of $\geq 99.00 \%$ to exactly one type strain were assigned the species ID of that type strain. For the genera Penicillium, Mucor, and Geotrichum, where known species complexes exist and database queries may result in unreliable identifications, ITS maximumlikelihood phylogenetic trees were constructed with sequences for type strains and isolates characterized in the study reported here. Penicillium type strains were acquired from the most recent verified reference database for the genus (Visagie et al., 2014). For Mucor and Geotrichum, no recent published verified reference databases are available. For these genera, the most recent publications providing DNA barcodes for type strains were hence used (De Hoog and Smith, 2004; Walther et al., 2013). Phylogenetic trees were constructed using the rapid maximum-likelihood algorithm RAxML (Stamatakis, 2006) with rapid bootstrapping and 100 bootstrap replicates (Supplemental Figures S1, S2, and S3; https://doi.org/10.3168/jds.2017-12635). Species-level identification was only assigned to isolates if the ITS sequence representing a specific AT associated with a given isolate clearly clustered with an ITS sequence of a single type specimen with a bootstrap value of $>50$ (Supplemental Table S2; https://doi.org/ 10.3168/jds.2017-12635). The same approach to construct phylogenetic trees was used to construct an ITS maximum-likelihood phylogenetic tree with all the ITS AT identified in the study reported here (Figure 1).

\section{RESULTS AND DISCUSSION}

\section{ITS Sequencing for Rapid and Reliable Characterization of Yeasts and Molds}

A total of 361 isolates obtained from raw milk and different dairy products as described above were characterized by ITS PCR amplification and sequencing; 346 isolates yielded ITS products that could be successfully sequenced. The remaining 15 isolates, none of which yielded PCR products with primers ITS4 and ITS5, were characterized by sequencing part of the gene that encodes D1/D2 domain of the nuclear large 
Tree scale: $0.1 \longmapsto$

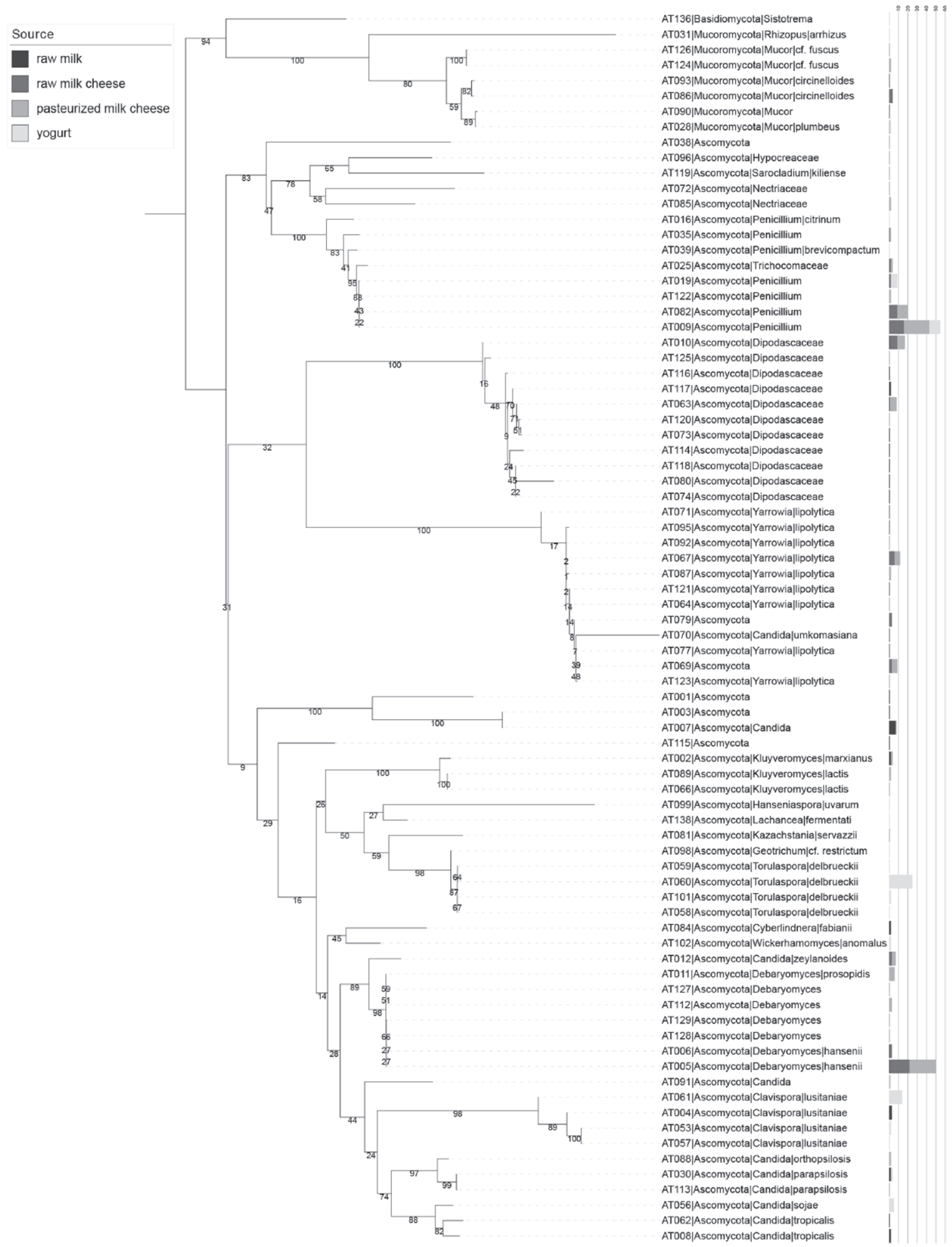

Figure 1. Midpoint-rooted maximum-likelihood (ML) phylogenetic tree of internal transcribed spacer (ITS) region sequences from fungal species isolated from raw milk (black), raw milk cheese (dark gray), pasteurized milk cheese (medium gray), and yogurt (light gray). Numerical values indicate the percentage of bootstrap replications (out of 100 total replications) that support the corresponding node. Species identification of allelic types (AT) was based on ITS region sequence analyses as described in Materials and Methods. Allele types that could not be identified to the species level with $a \geq 99.00 \%$ identity score were assigned the finest classification rank. 
subunit (LSU) (26S) rRNA. Thirteen of these isolates were successfully characterized by sequencing the D1/ D2 domain, whereas 2 isolates could not be successfully sequenced using either ITS or LSU primers. The 359 isolates that could be characterized by either ITS or LSU sequencing represented the phyla Ascomycota (347 isolates), Basidiomycota (1 isolate), and Mucoromycota (11 isolates). It is important to note that the phylumlevel classification of zygomycete fungi remains to be fully defined and clarified; although Mucoromycota represents the most current name for these organisms (Spatafora et al., 2016), the taxonomic classification of these organisms into phyla is likely to change.

Overall, the ITS sequence data for the 346 dairyassociated isolates from raw milk, raw and pasteurized milk cheeses, and yogurt yielded 81 unique ITS AT. Using the UNITE database (and Mycobank as needed), all 346 isolates that yielded ITS sequence data could be identified to at least the phylum level; 183 isolates could be assigned a species (based on an identity score of $\geq 99.00 \%$ against ITS region sequences in the UNITE Database) and 107 could be assigned a genus but not a species. The most common AT (AT9, 55 isolates) was classified as a Penicillium species, whereas the secondmost common AT (AT5, 50 isolates) was classified as Debaryomyces hansenii. Importantly, though, ITS AT-based species identifications should be interpreted carefully as current uncertainties as well as likely future changes in fungal taxonomy will affect ITS sequencingbased species identification. Furthermore, ITS sequencing does not provide high-resolution power for species complexes such as the Penicillium camemberti clade, Mucor circinelloides, and Geotrichum. Additional characterization methods, discussed below, are necessary to confidently assign species names for these organisms.

Overall, our data indicate that ITS sequencing allows straightforward initial characterization of the majority of fungal isolates obtained from dairy products: $96 \%$ of isolates yielded sequence data suitable for searches against the UNITE ITS database, with 107 and 183 isolates identified to the genus and species levels, respectively. Although we were able to find one large study that characterized 610 yeast and mold isolates from raw milk and raw milk cheeses (Lavoie et al., 2012), our study represents the largest molecular study characterizing yeast and mold isolates across diverse dairy products. Most other previous studies (Sulaiman et al., 2014; Banjara et al., 2015; Garnier et al., 2017) that used ITS sequencing for characterization of dairy isolates included fewer than 175 isolates. Importantly, our findings are consistent with previous studies that have shown that "ITS barcoding" provides for a standardized ITS AT nomenclature that can transcend taxonomic changes. In addition, our data showed considerable AT diversity among the dairy isolates characterized. We also found that ITS AT data can sometimes differentiate subtypes within a given species; for example, Clavispora lusitaniae included 4 different AT. This indicates that ITS-based AT data (even for isolates that cannot be identified to the genus or species level) can be used for isolate characterization, which can help dairy producers assess whether isolates obtained at different times or locations (e.g., in ingredients and finished product) may or may not have a common source. In some cases, this might allow for exclusion of a source, but more sensitive subtyping methods are needed to more definitively identify contamination sources. Specifically, even though ITS sequencing has high reliability for initial characterization and identification (given appropriate databases), it does not provide the highresolution power of other characterization and subtyping techniques (Stielow et al., 2015). Furthermore, intragenomic heterogeneities involving the ITS region have been documented in different fungal species such as Geotrichum candidum (Alper et al., 2011) and other yeast species including Candida glabrata, Candida tropicalis, Pichia norvegensis, and Saccharomyces cerevisiae (Zhao et al., 2015), potentially complicating ITS-based AT and species assignment. Importantly, sequencing different regions such as protein-coding genes may provide higher resolution at the species level. For example, Garnier et al. (2017) characterized 41 unique fungal species from 175 French yogurt and cheese isolates by using ITS sequencing as a preliminary step, followed by sequencing of protein-coding genes (e.g., partial $\beta$-tubulin gene and partial elongation factor 1- $\alpha$ ) for higher resolution power. If further discrimination beyond the species levels (i.e., subtyping) is required for fungal organisms, fragment analysis techniques such as amplified fragment length polymorphism (AFLP), microsatellites, and random amplified polymorphic DNA (RAPD) may be appropriate tools (Almeida and Araujo, 2013; Saghrouni et al., 2013).

\section{Ascomycetous Yeasts Are Primary Fungal Contaminants in Raw Milk}

The 38 fungal isolates obtained from raw milk samples (Table 2) all represented yeast, with no molds identified. For 4 isolates, the ITS PCR did not yield an amplicon, and LSU sequencing was successful for 3 of these isolates, which were classified as Pichia, Candida, and Ascomycota. The 34 isolates with ITS sequence data represented 21 different ITS AT; the most common AT among these isolates (AT7; 7 isolates) was classified as Candida. The remaining 20 AT found among the raw milk isolates each represented 3 or fewer isolates. Interestingly, one isolate was identified with LSU se- 
quence data as the yeast Pichia rhodanensis, a species that has not been previously reported as being isolated from raw milk (although other Pichia species have been reported from raw milk; Cocolin et al., 2002; Lavoie et al., 2012; Panelli et al., 2013). The most common genera identified among the 23 isolates with genus-level identification were Candida. The predominance of yeast isolates was not surprising because a recent review suggests that yeast populations of $10^{1}$ to $10^{3} \mathrm{cfu} / \mathrm{mL}$ of raw milk are typical (Fleet, 2011). The fact that Candida was a common genus identified among raw milk isolates is also consistent with previous reports (Cocolin et al., 2002; Lavoie et al., 2012). For example, Lavoie et al. (2012) found Candida species in 44\% of the 111 raw milk samples collected from farms in Quebec, Canada. Although Candida species have been linked to bovine mastitis (Watts, 1988; dos Santos and Marin, 2005), it is likely that yeasts such as Candida are introduced into raw milk from the dairy farm environment because Candida species are widely distributed in the environment and air (Torkar and Vengušt, 2008). In a study of 16 dairy farms in France, Vacheyrou et al. (2011) found that the same yeast species isolated from 9 stable and 3 milking parlor environments were also isolated from bulk tank raw milk of 14 of the farms. Importantly, Candida species are heat sensitive and easily killed during processing; studies indicate that most Candida strains, at $10^{5}$ cells $/ \mathrm{mL}$, can survive $20 \mathrm{~min}$ at $55^{\circ} \mathrm{C}$ but not 10 min at $62.5^{\circ} \mathrm{C}$ (Put et al., 1976).

\section{Debaromyces Is a Major Contributor to Fungal Microflora of Raw and Pasteurized Milk Cheeses}

Overall, 90 yeasts and molds isolated from 14 raw milk cheese samples and 150 yeasts and molds isolated from 33 pasteurized milk cheese samples (Table 1) were initially characterized by ITS sequencing. A total of 47 different ITS AT were identified among the 240 isolates. Among the 90 raw milk cheese isolates, the most common AT were classified as Debaryomyces hansenii (AT5; 21 isolates), Penicillium spp. (AT9; 16 isolates), Penicillium spp. (AT82; 9 isolates), and Dipodascaceae spp. (AT10; 8 isolates) (Table 2). The remaining 16 AT found among the raw milk cheese isolates each represented 6 or fewer isolates. Among the 150 pasteurized milk cheese isolates, the most common AT were classified as Debaryomyces hansenii (AT5; 28 isolates), Penicillium spp. (AT9; 27 isolates), Penicillium spp. (AT82; 11 isolates), and Dipodascaceae spp. (AT10; 8 isolates) (Table 2). The remaining 32 AT found among the pasteurized milk cheese isolates each represented 7 or fewer isolates. Consistent with our results, Wolfe et al. (2014)

Table 2. Unique internal transcribed spacer (ITS) allelic types (AT) isolated from raw milk, cheese, and yogurt

\begin{tabular}{|c|c|c|c|c|c|c|}
\hline \multirow[b]{2}{*}{ 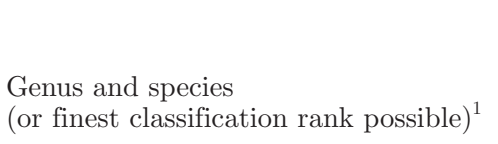 } & \multirow[b]{2}{*}{$\begin{array}{l}\text { ITS } \\
\text { AT }\end{array}$} & \multicolumn{4}{|c|}{ No. of isolates with a given AT obtained from: } & \multirow[b]{2}{*}{$\begin{array}{l}\text { Total no. } \\
\text { of isolates }\end{array}$} \\
\hline & & $\begin{array}{l}\text { Raw } \\
\text { milk }\end{array}$ & $\begin{array}{l}\text { Raw milk } \\
\text { cheese }\end{array}$ & $\begin{array}{l}\text { Pasteurized } \\
\text { milk cheese }\end{array}$ & Yogurt & \\
\hline \multicolumn{7}{|l|}{ Ascomycota } \\
\hline Ascomycota ${ }^{2}$ & 1 & 1 & & & & 1 \\
\hline Ascomycota $a^{2}$ & 3 & 1 & & & & 1 \\
\hline Ascomycota ${ }^{2}$ & 38 & & & 1 & & 1 \\
\hline Ascomycota ${ }^{2}$ & 115 & 1 & & & & 1 \\
\hline Ascomycota ${ }^{2}$ & 137 & & & & 1 & 1 \\
\hline Candida orthopsilosis & 88 & & & 2 & & 2 \\
\hline Candida parapsilosis & 30 & 2 & & & 2 & 4 \\
\hline Candida parapsilosis & 113 & & & 1 & & 1 \\
\hline Candida sojae & 56 & & & & 5 & 5 \\
\hline Candida spp. & 7 & 7 & & 1 & & 8 \\
\hline Clavispora lusitaniae & 4 & 3 & & & & 3 \\
\hline Clavispora lusitaniae & 53 & & & & 2 & 2 \\
\hline Clavispora lusitaniae & 57 & & & & 1 & 1 \\
\hline Clavispora lusitaniae & 61 & & & & 14 & 14 \\
\hline Cyberlindnera fabianii & 84 & 2 & & & & 2 \\
\hline Debaryomyces hansenii & 5 & 1 & 21 & 28 & & 50 \\
\hline Debaryomyces hansenii & 6 & 1 & 2 & & & 3 \\
\hline Debaryomyces prosopidis & 11 & & & 6 & & 6 \\
\hline Debaryomyces spp. & 112 & & & 3 & & 3 \\
\hline
\end{tabular}


Table 2 (Continued). Unique internal transcribed spacer (ITS) allelic types (AT) isolated from raw milk, cheese, and yogurt

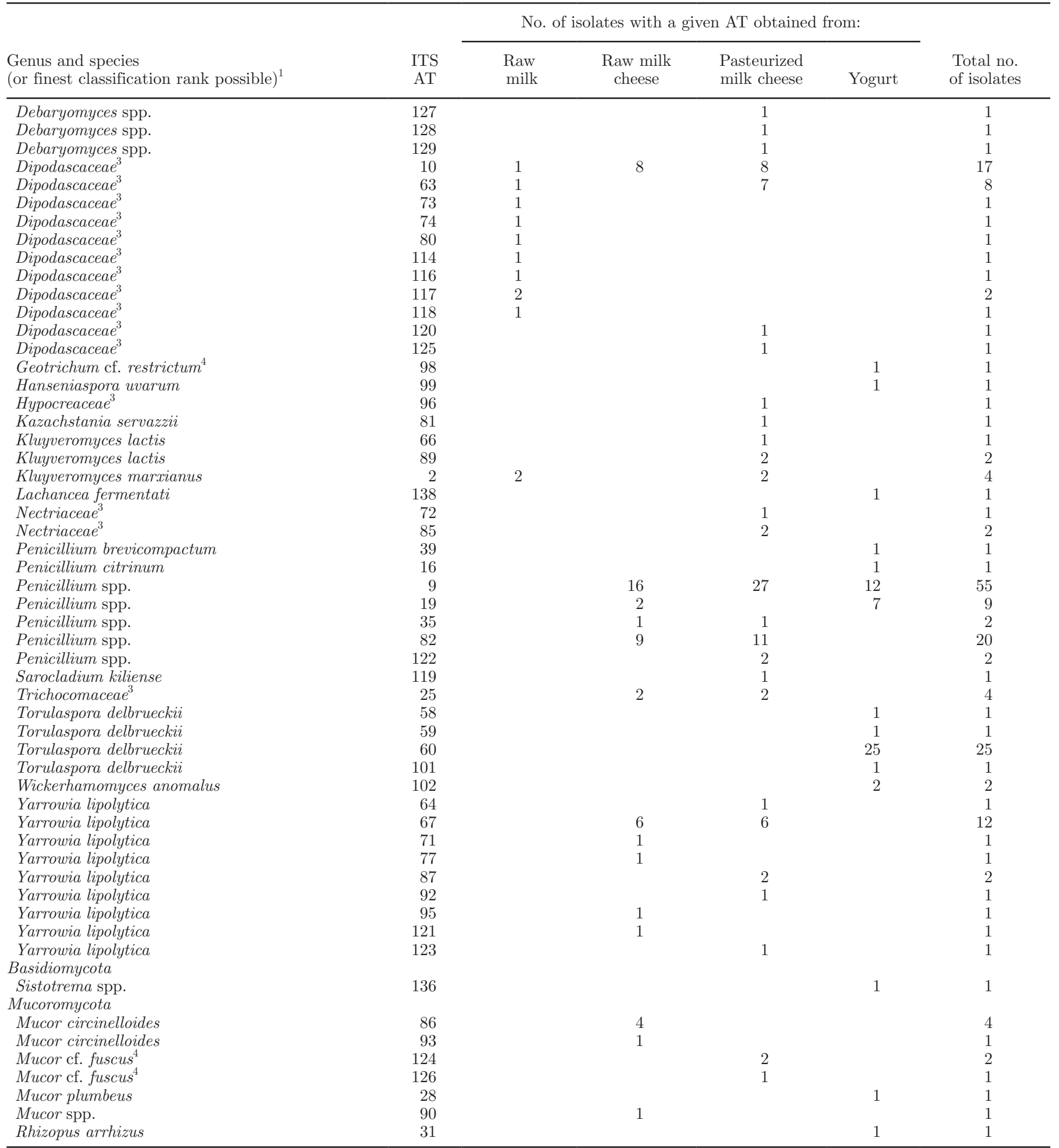

${ }^{1}$ Column subheaders (e.g., Ascomycota, Basidiomycota, and Mucoromycota) represent phyla.

${ }^{2}$ These ITS AT could only be identified to the phylum level.

${ }^{3}$ Represents a family-level classification.

${ }^{4}$ cf. [short for the Latin "confer" ("compare with")] signifies AT that resemble the given named species but where identification represents considerable uncertainty. 
previously reported isolation of a considerable diversity of fungal organisms from surfaces of different cheeses. When studying 137 cheese rinds from 10 different countries, this group identified 10 fungal genera that were consistent across all samples. Although we elected to not include cheeses that were clearly inoculated with fungal organisms (e.g., brie, blue cheese, bloomy rind cheeses, where the rind is intentionally inoculated with fungal organisms), we still reported considerable fungal diversity (at least 9 genera across 47 cheese samples). It is possible, however, that some cheeses included in our study reported here were deliberately inoculated through the washed rind process. Fungal organisms such as Debaryomyces hansenii, Geotrichum candidum, and Yarrowia lipolytica (all of which were isolated from cheeses in our study) can be included in the brine solution that is used to wash the cheese rind or may be directly sprayed to the cheese surface (Petersen et al., 2002; Bokulich and Mills, 2013). These organisms can be desirable in cheese and provide proteolytic and lipolytic enzymes as well as aroma compounds during the ripening process (Fleet, 1990). Thus, the frequency of the isolates from cheese reported below may include contaminants as well as deliberately inoculated organisms.

Fisher's exact test showed that there was no significant difference in the distribution of AT among raw and pasteurized milk cheese samples $(P>0.05)$; for this test, AT that occurred $<5$ times (combined frequency for raw and pasteurized cheese isolates) were combined into a single category ("uncommon ATs"). Consequently, combined results for raw and pasteurized milk cheese data are discussed below. Importantly, the observation that yeast and mold AT distribution does not differ between raw and pasteurized milk cheese samples suggests that contamination with these organisms occurs predominantly from the processing environment, consistent with the fact that the genera isolated here from cheeses are typically heat sensitive. For example, Wallace and Tanner (1931) showed that the conidia of Penicillium species are killed after heating for $5 \mathrm{~min}$ at $60^{\circ} \mathrm{C}$.

Among the raw and pasteurized milk cheese fungal isolates, the most common AT were identified as $D$. hansenii (AT5; 49 isolates), Penicillium spp. (AT9; 43 isolates), and Penicillium spp. (AT82; 20 isolates). The frequent occurrence of $D$. hansenii in a variety of cheeses is consistent with previous studies (Gardini et al., 2006; Capece and Romano, 2009; Padilla et al., 2014; Atanassova et al., 2016). For example, Capece and Romano (2009) sampled the curd and rind of 2 Pecorino di Filiano cheeses throughout each cheese's ripening time of $120 \mathrm{~d}$ and reported that $96 \%$ of cheese samples tested positive for $D$. hansenii. The occurrence of $D$. hansenii can be attributed to the ability of this species to grow in extreme environments such as high salt concentrations, low temperature, and low pH (Gori et al., 2012), and its ability to metabolize lactic and citric acids (Capece and Romano, 2009). Debaryomyces hansenii has also been isolated from brine solutions, raw milk, and dairy environments (Gori et al., 2012). In another study, Mounier et al. (2006) isolated the same D. hansenii strain from the surface of an Irish smear-ripened cheese as well as from the brine solution, processing equipment, and the hands of the workers in the dairy plant. These results mirror our results of frequent isolation of $D$. hansenii and suggest that it can colonize the surface of washedrind cheeses. The Penicillium section Fasciculata, series Camemberti clade includes dairy-relevant species such as $P$. camemberti and $P$. commune. These species are typically distinguished by their phenotypic characteristics: $P$. commune has blue-green conidia whereas $P$. camemberti has white conidia. Although $P$. camemberti is a desired organism in mold-ripened cheeses, P. commune is reported as one of the most frequently occurring spoilage molds in cheese; dairy isolates classified into this species have also been shown to grow rapidly at refrigeration temperatures (Lund et al., 1995; Kure et al., 2001; Hayaloglu and Kirbag, 2007). Growth of $P$. commune on cheese has been reported to result in discoloration of the surface and production of off-flavors (Lund et al., 2003). Overall, Penicillium species (e.g., $P$. commune, $P$. biforme) closely related to AT9 and AT82, which were found here to be common among raw and pasteurized milk cheeses isolates, have been shown to cause product defects that consumers can detect (Lund et al., 1995; Pitt and Hocking, 2009; Giraud et al., 2010). Prevention of contamination with these fungi (e.g., from environmental and raw material sources) is thus important to prevent quality issues with raw milk and pasteurized milk cheeses.

\section{Torulaspora delbrueckii Is a Major Contributor to Fungal Contamination in Yogurt}

In total, 59 yeasts and 24 molds were isolated from 30 yogurt samples (Table 1). Twenty-two different ITS AT were identified among these 83 isolates (Table 2). The most common AT represented Torulaspora delbrueckii (AT60; 25 isolates), Clavispora lusitaniae (AT61; 14 isolates), Penicillium spp. (AT9; 12 isolates), and Penicillium spp. (AT19; 7 isolates). The remaining 18 AT found among the yogurt isolates each represented 5 or fewer isolates.

Consistent with common identification of yeasts (e.g., Candida and Kluyveromyces) among yogurt isolates, yeasts are well documented as a major cause of spoilage in yogurt because the low $\mathrm{pH}$ of the product selects 
for their growth (Rohm et al., 1992; Mataragas et al., 2011; Krisch et al., 2014). For example, Suriyarachchi and Fleet (1981) reported that among 128 yogurt samples, the yeasts Candida famata and Kluyveromyces marxianus were isolated from 16 and $9 \%$ of samples, respectively, and represent the most frequently isolated species in their study. Likewise, Green and Ibe (1987) reported similar findings for 100 yogurt samples, with Clavispora lusitaniae, K. marxianus, and Candida krusei isolated from 65, 48, and 51 of samples, respectively.

Previous studies have reported the presence of $T$. delbrueckii in dairy products such as cheese (Westall and Filtenborg, 1998); however, to our knowledge, the current study is the first report of the presence of $T$. delbrueckii in yogurt. This finding could be attributed to the different methods used to identify the fungal isolates here and in previous studies. For example, Suriyarachchi and Fleet (1981) used physiological tests such as carbohydrate fermentation, nitrogen assimilation, and casein hydrolysis to characterize yeast isolates and then identified the isolates to the species level with the use of a standard key for yeast identification. The standard key used in Suriyarachchi and Fleet's study contained only 434 yeast species. In contrast, the UNITE database, which we used to query ITS region sequences, contains sequence identification information for over 24,000 ascomycetes, many of which would be classified as yeasts (Kõljalg et al., 2005). Consequently, it is possible that T. delbrueckii was previously isolated but not identified as this species. Importantly, this illustrates the advantages of using ITS sequencing, along with fungal sequence databases with high-quality reference ITS sequences, such as those in UNITE, for fungal characterization and identification.

The occurrence of molds in yogurt has not been widely reported. In one study, Sulaiman et al. (2014) documented Rhizomucor variabilis in 15 recalled Greek yogurt samples. In another study, Snyder et al. (2016) characterized Mucor circinelloides spoilage in yogurt. In this study, we documented the presence of Penicillium, Mucor, Rhizopus, and Sistotrema in yogurt. The occurrence of these genera in yogurt samples could suggest contamination from environmental sources, consistent with previous studies. Moist environments commonly found in dairy plants can support the growth of molds, which can lead to mold growth on floors, ceilings, walls, and drains (Sørhaug, 2011). Once in the dairy environment, mold spores can become airborne and contaminate the product (Salustiano et al., 2003). For example, Fleet (1990) reported that fungi may be present in the processing environment and can enter the product during packaging. Moreover, Snyder et al. (2016) hypothesized that $M$. circinelloides contamination in yogurt represented postprocessing contamination because the species is heat sensitive. Thus, these studies and our results suggest that fungal contaminants may be present in the dairy processing environment and can contaminate the product after heating.

\section{CONCLUSIONS}

Our data show that ITS sequencing is a useful and standardized tool for fungal classification, facilitated by a high PCR and sequencing success rate across a broad range of fungi as well as a large fungal sequence database (UNITE) with high-quality reference ITS sequences. However, additional databases and phylogenetic analyses are sometimes needed to identify fungal isolates from milk and dairy products. Ongoing realignments of fungal taxonomy can represent a challenge for meaningful identification of some isolates based on ITS sequences. Importantly however, ITS sequence data transcends taxonomic changes and isolate identification based on ITS data can easily be revised and updated as taxonomic changes are made. By using DNA sequencebased approaches, we demonstrated that fungi in dairy represent a broad diversity over multiple phyla. Overall, our data represent a step in developing new tools and approaches to better control dairy product spoilage due to fungal contaminants.

\section{ACKNOWLEDGMENTS}

This publication was made possible through a gift from Chobani Inc. (New Berlin, NY), supporting innovative research in dairy quality. We thank them for their generous contribution and commitment to food innovation and quality.

\section{REFERENCES}

Almeida, L. A., and R. Araujo. 2013. Highlights on molecular identification of closely related species. Infect. Genet. Evol. 13:67-75.

Alper, I., M. Frenette, and S. Labrie. 2011. Ribosomal DNA polymorphisms in the yeast Geotrichum candidum. Fungal Biol. 115:1259 1269.

Atanassova, M. R., C. Fernández-Otero, P. Rodríguez-Alonso, I. Fernández-No, J. Garabal, and J. Centeno. 2016. Characterization of yeasts isolated from artisanal short-ripened cows' cheeses produced in Galicia (NW Spain). Food Microbiol. 53:172-181.

Banjara, N., M. J. Suhr, and H. E. Hallen-Adams. 2015. Diversity of yeast and mold species from a variety of cheese types. Curr. Microbiol. 70:792-800.

Bokulich, N. A., and D. A. Mills. 2013. Facility-specific "house" microbiome drives microbial landscapes of artisan cheesemaking plants. Appl. Environ. Microbiol. 79:5214-5223.

Callon, C., F. Duthoit, C. Delbès, M. Ferrand, Y. Le Frileux, R. De Crémoux, and M.-C. Montel. 2007. Stability of microbial communities in goat milk during a lactation year: Molecular approaches. Syst. Appl. Microbiol. 30:547-560.

Capece, A., and P. Romano. 2009. "Pecorino di Filiano" cheese as a selective habitat for the yeast species, Debaryomyces hansenii. Int. J. Food Microbiol. 132:180-184. 
Cocolin, L., D. Aggio, M. Manzano, C. Cantoni, and G. Comi. 2002. An application of PCR-DGGE analysis to profile the yeast populations in raw milk. Int. Dairy J. 12:407-411.

Crous, P. W., W. Gams, J. A. Stalpers, V. Robert, and G. Stegehuis. 2004. MycoBank: An online initiative to launch mycology into the 21st century. Stud. Mycol. 50:19-22.

De Hoog, G. S., and M. T. Smith. 2004. Ribosomal gene phylogeny and species delimitation in Geotrichum and its teleomorphs. Stud. Mycol. 50:489-515.

Delavenne, E., J. Mounier, K. Asmani, J.-L. Jany, G. Barbier, and G. Le Blay. 2011. Fungal diversity in cow, goat and ewe milk. Int. J. Food Microbiol. 151:247-251.

dos Santos, R. C., and J. M. Marin. 2005. Isolation of Candida spp. from mastitic bovine milk in Brazil. Mycopathologia 159:251-253.

Edgar, R. C. 2004. MUSCLE: Multiple sequence alignment with high accuracy and high throughput. Nucleic Acids Res. 32:1792-1797.

Fleet, G. H. 1990. Yeasts in dairy products. J. Appl. Bacteriol. 68:199211.

Fleet, G. H. 2011. Yeast spoilage of foods and beverages. Pages 53-63 in The Yeasts. 5th ed. Elsevier, London, UK.

Fröhlich-Wyder, M.-T. 2003. Yeasts in dairy products. Pages 209-237 in Yeasts in Food. Woodhead Publishing, Boca Raton, FL.

Gardini, F., R. Tofalo, N. Belletti, L. Iucci, G. Suzzi, S. Torriani, M. Guerzoni, and R. Lanciotti. 2006. Characterization of yeasts involved in the ripening of Pecorino Crotonese cheese. Food Microbiol. 23:641-648

Garnier, L., F. Valence, A. Pawtowski, L. Auhustsinava-Galerne, N. Frotté, R. Baroncelli, F. Deniel, E. Coton, and J. Mounier. 2017. Diversity of spoilage fungi associated with various French dairy products. Int. J. Food Microbiol. 241:191-197.

Giraud, F., T. Giraud, G. Aguileta, E. Fournier, R. Samson, C. Cruaud, S. Lacoste, J. Ropars, A. Tellier, and J. Dupont. 2010. Microsatellite loci to recognize species for the cheese starter and contaminating strains associated with cheese manufacturing. Int. J. Food Microbiol. 137:204-213.

Gori, K., L. M. Sørensen, M. A. Petersen, L. Jespersen, and N. Arneborg. 2012. Debaryomyces hansenii strains differ in their production of flavor compounds in a cheese-surface model. MicrobiologyOpen 1:161-168.

Green, M. D., and S. N. Ibe. 1987. Yeasts as primary contaminants in yogurts produced commercially in Lagos, Nigeria. J. Food Prot. 50:193-205.

Hayaloglu, A. A., and S. Kirbag. 2007. Microbial quality and presence of moulds in Kuflu cheese. Int. J. Food Microbiol. 115:376-380.

Jacques, N., and S. Casaregola. 2008. Safety assessment of dairy microorganisms: The hemiascomycetous yeasts. Int. J. Food Microbiol. 126:321-326.

Kõljalg, U., K. H. Larsson, K. Abarenkov, R. H. Nilsson, I. J. Alexander, U. Eberhardt, S. Erland, K. Høiland, R. Kjøller, and E. Larsson. 2005. UNITE: A database providing web-based methods for the molecular identification of ectomycorrhizal fungi. New Phytol. 166:1063-1068.

Krisch, J., J. Csanádi, and C. Vágvölgyi. 2014. Fungi in and on dairy products. Pages 159-169 in Progress in Mycological Research: Fungi from Different Substrates. CRC Press, London, UK.

Kure, C. F., E. Borch, I. Karlsson, J. P. Homleid, and S. Langsrud 2008. Use of the selective agar medium CREAD for monitoring the level of airborne spoilage moulds in cheese production. Int. J. Food Microbiol. 122:29-34.

Kure, C. F., Y. Wasteson, J. Brendehaug, and I. Skaar. 2001. Mould contaminants on Jarlsberg and Norvegia cheese blocks from four factories. Int. J. Food Microbiol. 70:21-27.

Kurtzman, C. P., and C. J. Robnett. 1998. Identification and phylogeny of ascomycetous yeasts from analysis of nuclear large subunit (26S) ribosomal DNA partial sequences. Antonie van Leeuwenhoek 73:331-371.

Lavoie, K., M. Touchette, D. St-Gelais, and S. Labrie. 2012. Characterization of the fungal microflora in raw milk and specialty cheeses of the province of Quebec. Dairy Sci. Technol. 92:455-468.
Ledenbach, L. H., and R. T. Marshall. 2009. Microbiological spoilage of dairy products. Pages 41-67 in Compendium of the Microbiological Spoilage of Foods and Beverages. Springer, New York, NY.

Lund, F., O. Filtenborg, and J. Frisvad. 1995. Associated mycoflora of cheese. Food Microbiol. 12:173-180.

Lund, F., A. B. Nielsen, and P. Skouboe. 2003. Distribution of Penicillium commune isolates in cheese dairies mapped using secondary metabolite profiles, morphotypes, RAPD and AFLP fingerprinting. Food Microbiol. 20:725-734.

Mataragas, M., V. Dimitriou, P. N. Skandamis, and E. H. Drosinos. 2011. Quantifying the spoilage and shelf-life of yoghurt with fruits. Food Microbiol. 28:611-616.

Mayoral, M. B., R. Martín, A. Sanz, P. E. Hernández, I. González, and T. García. 2005. Detection of Kluyveromyces marxianus and other spoilage yeasts in yoghurt using a PCR-culture technique. Int. J. Food Microbiol. 105:27-34.

Mounier, J., S. Goerges, R. Gelsomino, M. Vancanneyt, K. Vandemeulebroecke, B. Hoste, N. Brennan, S. Scherer, J. Swings, and G. Fitzgerald. 2006. Sources of the adventitious microflora of a smear-ripened cheese. J. Appl. Microbiol. 101:668-681.

Newkirk, R. W., J. B. Bender, and C. W. Hedberg. 2012. The potential capability of social media as a component of food safety and food terrorism surveillance systems. Foodborne Pathog. Dis. 9:120-124.

Padilla, B., P. Manzanares, and C. Belloch. 2014. Yeast species and genetic heterogeneity within Debaryomyces hansenii along the ripening process of traditional ewes' and goats' cheeses. Food Microbiol. 38:160-166.

Panelli, S., E. Brambati, C. Bonacina, and M. Feligini. 2013. Diversity of fungal flora in raw milk from the Italian Alps in relation to pasture altitude. Springerplus 2:405.

Petersen, K. M., S. Westall, and L. Jespersen. 2002. Microbial succession of Debaryomyces hansenii strains during the production of Danish surfaced-ripened cheeses. J. Dairy Sci. 85:478-486.

Pitkäranta, M., T. Meklin, A. Hyvärinen, L. Paulin, P. Auvinen, A. Nevalainen, and H. Rintala. 2008. Analysis of fungal flora in indoor dust by ribosomal DNA sequence analysis, quantitative PCR, and culture. Appl. Environ. Microbiol. 74:233-244.

Pitt, J. I., and A. D. Hocking. 2009. Fungi and Food Spoilage. 3rd ed. Springer, New York, NY.

Put, H. M., J. De Jong, F. Sand, and A. Van Grinsven. 1976. Heat resistance studies on yeast spp. causing spoilage in soft drinks. J. Appl. Bacteriol. 40:135-152.

Rohm, H., F. Eliskases-Lechner, and M. Bräuer. 1992. Diversity of yeasts in selected dairy products. J. Appl. Bacteriol. 72:370-376.

Saghrouni, F., J. Ben Abdeljelil, J. Boukadida, and M. Ben Said. 2013 Molecular methods for strain typing of Candida albicans: A review. J. Appl. Microbiol. 114:1559-1574.

Salustiano, V. C., N. J. Andrade, S. C. C. Brandão, R. M. C. Azeredo, and S. A. K. Lima. 2003. Microbiological air quality of processing areas in a dairy plant as evaluated by the sedimentation technique and a one-stage air sampler. Braz. J. Microbiol. 34:255-259.

Schoch, C. L., K. A. Seifert, S. Huhndorf, V. Robert, J. L. Spouge, C. A. Levesque, W. Chen, and F. B. Consortium. 2012. Nuclear ribosomal internal transcribed spacer (ITS) region as a universal DNA barcode marker for fungi. Proc. Natl. Acad. Sci. USA 109:6241-6246.

Snyder, A. B., J. J. Churey, and R. W. Worobo. 2016. Characterization and control of Mucor circinelloides spoilage in yogurt. Int. J. Food Microbiol. 228:14-21.

Sørhaug, T. 2011. Spoilage molds in dairy products. Pages 780-784 in Encyclopedia of Dairy Sciences. 2nd ed. Academic Press, San Diego, CA.

Spatafora, J. W., Y. Chang, G. L. Benny, K. Lazarus, M. E. Smith, M. L. Berbee, G. Bonito, N. Corradi, I. Grigoriev, and A. Gryganskyi. 2016. A phylum-level phylogenetic classification of zygomycete fungi based on genome-scale data. Mycologia 108:1028-1046.

Stamatakis, A. 2006. RAxML-VI-HPC: Maximum likelihood-based phylogenetic analyses with thousands of taxa and mixed models. Bioinformatics 22:2688-2690. 
Stielow, J. B., C. A. Lévesque, K. A. Seifert, W. Meyer, L. Iriny, D. Smits, R. Renfurm, G. J. M. Verkley, M. Groenewald, D. Chaduli, A. Lomascolo, S. Welti, L. Lesage-Meessen, A. Favel, A. M. S. Al-Hatmi, U. Damm, N. Yilmaz, J. Houbraken, L. Lombard, W. Quaedvlieg, M. Binder, L. A. I. Vaas, D. Vu, A. Yurkov, D. Begerow, O. Roehl, M. Guerreiro, A. Fonseca, K. Samerpitak, A. D. van Diepeningen, S. Dolatabadi, L. F. Moreno, S. Casaregola, S. Mallet, N. Jacques, L. Roscini, E. Egidi, C. Bizet, D. GarciaHermoso, M. P. Martín, S. Deng, J. Z. Groenewald, T. Boekhout, Z. W. de Beer, I. Barnes, T. A. Duong, M. J. Wingfield, G. S. de Hoog, P. W. Crous, C. T. Lewis, S. Hambleton, T. A. A. Moussa, H. S. Al-Zahrani, O. A. Almaghrabi, G. Louis-Seize, R. Assabgui, W. McCormick, G. Omer, K. Dukik, G. Cardinali, U. Eberhardt, M. de Vries, and V. Robert. 2015. One fungus, which genes? Development and assessment of universal primers for potential secondary fungal DNA barcodes. Persoonia 35:242-263.

Sulaiman, I. M., E. Jacobs, S. Simpson, and K. Kerdahi. 2014. Molecular identification of isolated fungi from unopened containers of Greek yogurt by DNA sequencing of internal transcribed spacer region. Pathogens 3:499-509.

Suriyarachchi, V. R., and G. H. Fleet. 1981. Occurrence and growth of yeasts in yogurts. Appl. Environ. Microbiol. 42:574-579.

Temelli, S., Ş. Anar, C. Sen, and P. Akyuva. 2006. Determination of microbiological contamination sources during Turkish white cheese production. Food Contr. 17:856-861.

Torkar, K. G., and A. Vengušt. 2008. The presence of yeasts, moulds and aflatoxin M 1 in raw milk and cheese in Slovenia. Food Contr. 19:570-577.

Vacheyrou, M., A.-C. Normand, P. Guyot, C. Cassagne, R. Piarroux, and Y. Bouton. 2011. Cultivable microbial communities in raw cow milk and potential transfers from stables of sixteen French farms. Int. J. Food Microbiol. 146:253-262.

Vangay, P., E. B. Fugett, Q. Sun, and M. Wiedmann. 2013. Food microbe tracker: A web-based tool for storage and comparison of food-associated microbes. J. Food Prot. 76:283-294.

Visagie, C. M., J. Houbraken, J. C. Frisvad, S. B. Hong, C. H. W Klaassen, G. Perrone, K. A. Seifert, J. Varga, T. Yaguchi, and R. A. Samson. 2014. Identification and nomenclature of the genus Penicillium. Stud. Mycol. 78:343-371.

Wallace, G., and F. Tanner. 1931. Effect of heat on mold spores. Exp. Biol. Med. 28:970-972.

Walther, G., J. Pawłowska, A. Alastruey-Izquierdo, M. Wrzosek, J. Rodriguez-Tudela, S. Dolatabadi, A. Chakrabarti, and G. de Hoog. 2013. DNA barcoding in Mucorales: An inventory of biodiversity. Persoonia 30:11-47.

Watts, J. L. 1988. Etiological agents of bovine mastitis. Vet. Microbiol. 16:41-66.

Westall, S., and O. Filtenborg. 1998. Spoilage yeasts of decorated soft cheese packed in modified atmosphere. Food Microbiol. 15:243249

Wolfe, B. E., J. E. Button, M. Santarelli, and R. J. Dutton. 2014 Cheese rind communities provide tractable systems for in situ and in vitro studies of microbial diversity. Cell 158:422-433.

Zhao, Y., C.-C. Tsang, M. Xiao, J. Cheng, Y. Xu, S. K. Lau, and P. C. Woo. 2015. Intra-genomic internal transcribed spacer region sequence heterogeneity and molecular diagnosis in clinical microbiology. Int. J. Mol. Sci. 16:25067-25079. 